\title{
INNOVATION ECOSYSTEMS IN BRAZIL: RESEARCH UNIVERSITIES AS DRIVERS OF COMPETITIVENESS
}

Paola Rücker Schaeffer ${ }^{1}$ Bruno Brandão Fischer ${ }^{1}$

Sergio R Queiroz ${ }^{1}$

${ }^{1}$ Universidade Estadual de Campinas 
INNOVATION ECOSYSTEMS IN BRAZIL: RESEARCH UNIVERSITIES AS DRIVERS OF COMPETITIVENESS

\begin{abstract}
Universities are increasingly perceived as agents involved with regional development. It is now recognized that academic contributions to the socioeconomic environment go well beyond scientific investigations and teaching activities, incorporating market-oriented initiatives to the academic mission. However, these effects are geographically bounded. Given these conditions, this article aims at addressing universities' impacts upon output vectors of localized innovation ecosystems. Using data from cities and microregions in the State of São Paulo, Brazil, we address universities impacts on the local-level generation of patents and utility models, software production and emergence of knowledge-intensive entrepreneurship. Findings support the proposition that major academic institutions lie at the heart of innovation ecosystems, but impacts are mostly local, happening more strongly at the level of cities.
\end{abstract}

Keywords: Regional Systems of Innovation; Innovation Ecosystems; Universities.

\title{
1 INTRODUCTION
}

Universities can be perceived as institutions that shape research activities, create a supply of qualified labor, generate and diffuse knowledge across socioeconomic systems (Clark, 2004; Etzkowitz \& Leydesdorff, 2000). Accordingly, they function as agents involved with regional development through direct and indirect contributions to productive structures (Mowery \& Sampat, 2005). It is within this context that the 'entrepreneurial university' concept has gained ground (Etzkowitz, 1998, 2004). Following this rationale, universities' contributions to society go well beyond scientific investigations and teaching activities, incorporating market-oriented initiatives to the academic mission. Such perspective adds emphasis to university-industry interactions, research contracts, consultancy, patenting and licensing of research results, as well as academic entrepreneurship materialized in the concept of universities' (Bercovitz \& Feldman, 2006; D’Este \& Perkmann, 2011; Perkmann et al., 2013).

In this regard, literature underscores the key role performed by these institutions within the context of innovation ecosystems. Main impacts are attributed to the supply of human capital (Benneworth \& Hospers, 2007; Youtie \& Shapira, 2008), collaborative research with industry leading to an upsurge in patenting, co-patenting and scientific publications (Cowan \& Zinovyeva, 2013; Hong, 2008; Jaffe, 1989; Fritsch \& Slavtchev, 2007; Wal \& Boschma, 2009), and spawning new, knowledge-intensive businesses (Agrawal \& Cockburn, 2003; Feldman, 2001; Saxenian, 2006; Wef, 2013). Consequently, academia can not only enhance capabilities in incumbents, but also be responsible for creating entirely new enterprises (Collini, 2012).

However, these effects are geographically bounded as they are connected to the industrial structure of each region, the characteristics of its firms, patterns of existing connections among agents and intrinsic traits of individual universities (Agrawal \& Cockburn, 2003; Bercovitz \& Feldman, 2006; Buesa et al., 2006). Hence, it is not the mere presence of universities that drives the consolidation of innovation ecosystems (Brown, 2016). It is needed a 'soft' infrastructure, 
consisting in dynamic of relationships involving universities, research institutes, firms and other support institutions. These are the conditions needed for the generation of human resources that fit regional needs, as well as for the accumulation and transfer of knowledge (Buesa et al., 2006).

Given these conditions, this article aims at addressing universities' impacts upon output vectors of localized innovation ecosystems. We want to further understand the extent of academic contributions to these productive structures. Additionally, we also target distinct geographical units to assess the spatial reach if such effects. In order to accomplish these goals we assess data from the State of São Paulo, Brazil. The application of the empirical model comprises data coming from 645 cities and 43 microregions observed throughout the period 2002-2014. As indicators of innovation ecosystems' output we look into patents and utility models, software production and emergence of knowledge-intensive entrepreneurship (KIE) activity. Estimations control for other vectors of interest, comprehending market size, agglomeration economies, localization economies, local infrastructure, and internationalization. Findings support the proposition that major academic institutions lie at the heart of innovation ecosystems, but impacts are mostly local, happening more strongly at the level of cities.

This research gains relevance for dealing with the context of an emerging country. Besides the scant available evidence on innovation ecosystems located outside developed economies, dealing with a developing country also means we are addressing an analytical unit in which universities play a featured role in terms of knowledge production and diffusion - a function of weak competences of local firms. Hence, in nations that lag behind in innovation activities, universities can be understood as institutions capable of leveraging aggregate competitiveness, thus shaping the conditions for catching-up processes (Mazzoleni \& Nelson, 2007; Suzigan \& Albuquerque, 2011; Suzigan et al., 2009).

This article is structured in five sections. After this introduction, Section 2 discusses the theoretical background and empirical findings on innovation ecosystems. Special focus is given to the role played by universities in this debate. Section 3 depicts the methodological procedures and the dataset. Results are presented in Section 4 and Section 5 concludes with final remarks, implications and avenues for future research.

\section{INNOVATION ECOSYSTEMS}

The growing importance attributed to innovation as a mechanism of economic development has generated a large body of research that aims at understanding how agents and their respective patterns of interaction are related - and how, ultimately, they can boost innovative capabilities. One approach of key interest within this scope deals with the dynamics of Regional Systems of Innovation. These local units are defined as systems "in which firms and other organizations are systematically engaged in interactive learning through an institutional milieu characterized by embeddedness" (Cooke et al., 1998, p. 1581).

Regional Systems of Innovation - or innovation ecosystems as they have been addressed more recently - are characterized by innovative activities that rely on collaborative arrangements between firms and local institutions, involving universities, research institutes, technology transfer offices, sources of funding and others. Within this context, innovation culture and policy are fundamental drivers in setting the conditions for interactions to take place (Asheim \& Isaksen, 2002; Cooke et al., 1997; Doloreux, 2002; Doloreux \& Parto, 2005). This (eco)systemic nature of relationships can only arise in local context where the productive

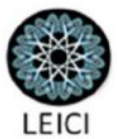


(knowledge exploitation subsystem) and the knowledge (knowledge generation subsystem) structures are engaged in processes of interactive learning (Clarysse et al., 2014; Cooke, 2001; Jiao et al., 2016). Hence, innovation ecosystems/regional systems can be understood as dynamic systems, possessing an inherently social character and being composed by the interaction of its subsystems (Cooke, 2005; Uyarra, 2010).

The main argument behind this rationale is related to the idea that the generation and diffusion of innovations, as well as entrepreneurial activity, are shaped by the local infrastructure, its externalities, specialized services and levels of trust involved in relationships between agents. In its turn, these dynamics lead to localized economic development (Alvedalen \& Boschma, 2017). One of the key aspects in this debate concerns the existence of multidimensional contexts, dependent on the interactions among agents (non-linearity), characterized by systemic relationships and bound by historical trajectories that lead to spatially constrained learning processes. This latter proposition is a function of the fact that networks of interaction are fundamentally embedded in local productive structures, since geographical proximity is a main determinant of knowledge sharing (Agrawal \& Cockburn, 2003; Asheim et al., 2011), especially those of a tacit nature (Leydesdorff \& Fritsch, 2006; Cooke, 2008).

Hence, spatial proximity, the existence of common institutions, along with formal and informal mechanisms forging trust in relationships, facilitate effective knowledge flows (Asheim \& Coenen, 2005; Cooke, 2001; Jackson, 2011; Uyarra, 2010; Wal \& Boschma, 2009). In addition, the diffusion of knowledge between firms is also influenced by other elements, such as the distinct learning trajectories and capability building processes of firms (Boschma, 2005; Breschi \& Lissoni, 2009; Doloreux, 2002; Dosi, 1988; Giuliani, 2013).

Furthermore, spatial proximity is of utmost relevance for establishing interactions with universities and research institutes (Fritsch, 2001; Fritsch \& Slavtchev, 2007; Moodysson et al., 2008; Uyarra, 2010), making the case for academic units to be considered as 'anchors' of innovation ecosystems, fostering aggregate competitiveness at the local level (Xu et al., 2017). This situation underscores the importance assigned to universities as central agents in processes of knowledge absorption and diffusion within regions, also connecting agents to external systems and reducing risks of lock-in (Fritsch \& Schwirten, 2006).

\subsection{Universities at the Heart of Innovation Ecosystems}

Universities are agents that generate and diffuse knowledge, also promoting regional development through its connections with the socioeconomic environment (Jiao et al., 2016; Poods et al., 2010). Accordingly, these academic institutions lie at the heart of innovation ecosystems, feeding the local context with qualified labor, interacting with local businesses, generating patents (and licensing these patents) and new ventures, attracting investments from incumbents, and acquiring and disseminating external knowledge (Benneworth \& Hospers, 2007; Bercovitz \& Feldman, 2006; Fritsch \& Schwirten, 2006; Galan-Muros \& Davey, 2017; Harrison \& Leitch, 2010; Youtie \& Shapira, 2008). These activities grant universities an entrepreneurial character, comprising market-related initiatives (Etzkowitz, 1998, 2004; Siegel \& Wright, 2015).

As already outlined, spatial proximity matters when accounting for the impacts of universities upon the dynamics of innovation ecosystems (Hong, 2008; Jiao et al., 2016), a function of the high levels of tacit knowledge involved in the knowledge flows between academia and industry (Fritsch \& Schwirten, 2006). Illustratively, Ács et al. (2002) identify that effects of academic R\&D in the United States arte circumscribed to a radius of roughly 75

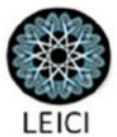


miles. Fritsch (2005) corroborates with these findings, pointing out that university-industry relationships in Europe are essentially local. Such effects are magnified when the analytical subject concerns academic spin offs, whereas location of new ventures is closely connected to the location of universities (Asheim et al., 2011; Harrison \& Leitch, 2010).

The role attributed to universities in the dynamics of innovation ecosystems is even more critical when the focus is directed towards the context of developing countries (Chen \& Kenney, 2007; Cowan \& Zinovyeva, 2013). In these countries, universities stand out as influential agents in the process of technological upgrading and catch up (Jiao et al., 2016; Li, 2009; Youtie \& Shapira, 2008). This happens as a consequence of low levels of innovative capabilities embedded in firms, making academia a strategic source of information, knowledge and innovation (Rapini et al., 2009).

However, this is far from representing a deterministic character associated to universities' contributions to innovation ecosystems. Even if its local presence can be interpreted as a prerequisite for regional systems of innovation (Bercovitz \& Feldman, 2006; Hong, 2008), other elements of the technological infrastructure and the very quality of universities' research capabilities are indispensable for knowledge flows to occur and confer itself and other agents with enhanced competitiveness (Cowan \& Zinovyeva, 2013).

\subsection{Universities' Spillovers}

Patents are recognized by literature as a key vector of interest when analyzing economic impacts of universities at the local level. Accordingly, the generation of intellectual property seems to be positively affected by academic expenditures in research activities (Jaffe, 1989). Agrawal and Cockburn (2003), Cowan and Zinovyeva (2013) and Li (2009) observe the existence of a 'co-location' effect between overall patenting activity in a given technological domain and the existence of strong academic research in the same domain in the same region. Buesa et al. (2010) identify universities as determinants of per capita patenting activity. Moreover, patent deposits performed by firms have a high propensity of citing academic publications that are produced in the same area, highlighting the spatial boundedness of these connections (Hicks et al., 2001).

In its turn, the generation of academic spin offs can also be deemed as an important source of economic impact arising from universities within the context of innovation ecosystems (Bercovitz \& Feldman, 2006; Chen \& Kenney, 2007; WEF, 2014). Following this rationale, the importance of academic entrepreneurship as a mechanism of research commercialization has received increasing attention from the literature on entrepreneurial universities (Galan-Muros $\&$ Davey, 2017). Since new ventures are mostly embedded in social relations, their creation often takes place within ecosystems where universities have established connections with other agents (Alvedalen \& Boschma, 2017). Besides, universities can be considered as key drivers in instituting and developing new knowledge-intensive firms, as identified in the case of Beijing (Chen \& Kenney, 2007). This way, universities take on a double function, interacting and collaborating not only with incumbents, but also giving birth to new enterprises (Collini, 2012). Therefore, we expect, in emerging countries, knowledge-intensive entrepreneurial activity to be significantly influenced by the local presence of academia within innovation ecosystems, following recent evidence 


\section{METHODOLOGICAL PROCEDURES AND DATA}

A first step in our assessment consists in assembling an empirical model aiming at testing the role of universities in shaping the capabilities of innovation ecosystems. As exposed in our theoretical background, the underlying hypothesis of this model must reflect expectations that academic institutions function as central agents within local and regional dynamics of innovative activity (Asheim et al., 2011; Autio, 1998; Bercovitz \& Feldman, 2006; Clarysse et al., 2014; Cooke et al., 1997; Diez, 2000; Guerrero et al., 2016; Mazzoleni \& Nelson, 2007). To this end we propose the following analytical structure:

$$
Y_{i t}=\alpha+\operatorname{Univ}_{i t}^{\beta}+\sum i \Omega_{i t}^{\theta}+\varepsilon_{i t}
$$

Equation 1

Where $Y_{i t}$ represents any given output of innovation ecosystems in location ' $i$ ' in time ' $\mathrm{t}$ '. $\alpha$ is a constant. $U n i v_{i t}^{\beta}$ stands for universities impacts on the outcomes with elasticity $\beta$. The term $\sum i \Omega_{i t}^{\theta}$ comprehends the aggregate behaviour of controls and other potential sources of influence on $Y_{i t}$ with a combined elasticity $\theta$. Mains effects here can be associated to local market dynamics, infrastructure and level of internationalization (see table 1 for a description of operational variables). $\boldsymbol{\varepsilon}_{i t}$ is the model's error term.

The application of the empirical model comprises data coming from 645 cities and 43 microregions $^{i}$ in the State of São Paulo observed throughout 13 years (2002-2014). This geographic scope considers that city-level analysis stands for an adequate object for the evaluation of innovation ecosystems (Qian et al., 2013), but expansion of the appraisal can offer insights on the spatial reach of universities' influence on innovation dynamics. The complete set of analytical variables is depicted in Table 1.

\section{Table 1. Analytical variables}

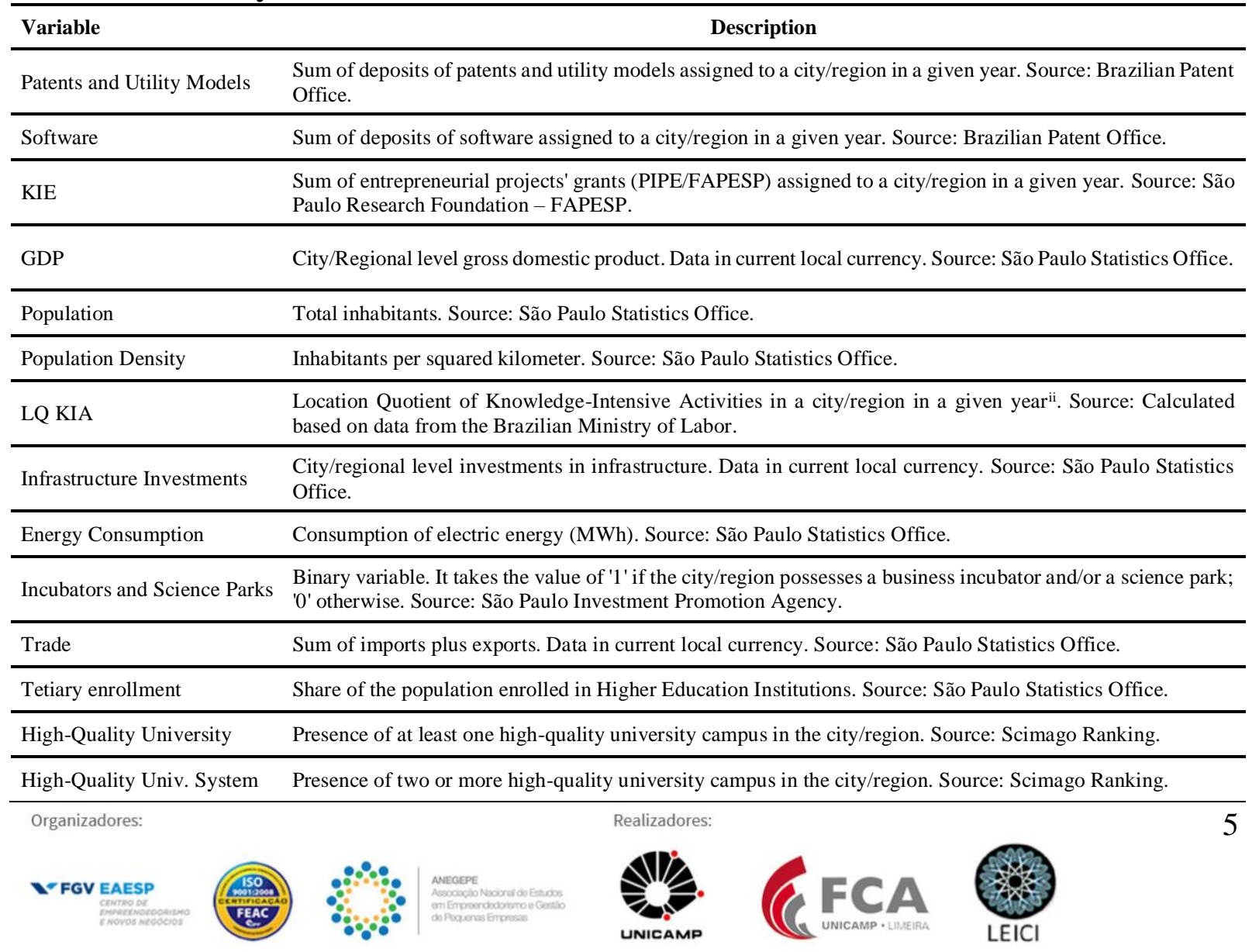


Our outcome variable, $Y$, is assessed through three different indicators, aiming at generating a multidimensional perspective of innovation ecosystems, namely: (i) patents and utility models; (ii) software production; and (iii) knowledge-intensive entrepreneurship (KIE) activity. While the first two variables are straightforwardly represented by traditional intellectual property statistics, KIE activity is approximated by the number of PIPE projects within a city/region in a given year. This program is an initiative from FAPESP (the research funding agency of the State of São Paulo) to support innovation in small enterprises, resembling in structure and objectives the Small Business Innovation Research (SBIR) program in the United States iii. We estimate the model for KIE including transformed (binary) forms of patenting activity and software production, as these indicators can feed entrepreneurs with inputs for firm-level innovation ${ }^{\text {iv }}$.

Our main target concerns the presence of high-quality academic universities as an influential agent within the dynamics of innovation ecosystems. In order to achieve robust results, incidence of these institutions was differentiated between the presence of: (i) at least one campus of a high-quality university; and (ii) presence of a 'system' of high-quality university campuses, i.e, presence of two or more units of these institutions at the city/regionallevel. The use of dummy variables follows the analytical approach found in Fischer et al. (2018a), and Alcácer and Chung (2007). Focus top-tier institutions is based on Laursen et al. (2011).

The operational definition high-quality universities was built upon institutions located in the State of São Paulo and appearing in the Scimago ranking ${ }^{\mathrm{v}}$. Non-university institutions were excluded. We also excluded universities that did not consistently qualify for the ranking. We interpreted this situation as an indicator of 'shaky' quality. If an institution entered the ranking and remained for at least four years in a row, we added it as a high-quality university beginning in its first year of inclusion. This procedure allows adding universities that have demonstrated improved quality over the analytical period. Furthermore, some institutions and campuses began operations after the initial year in the analysis, so we controlled effects to start either when the campus started its operation (in the case of being a campus belonging to an institution already identified as high quality) or, in the case of a new institution, when it achieved 'highquality' status according to the defined parameters.

In total, we have a sample of fifteen high-quality universities located in 37 cities and 25 microregions. In order to verify the robustness of our procedure, we cross-checked our sample with data from the São Paulo Research Foundation (FAPESP) Grants and Scholarships database. Locations selected as having high-quality universities corresponded to the group of relevant cities/microregions in terms of research funding. We complement this analysis with the variable Tertiary Enrollment. While this indicator somewhat overlaps with the presence of high-quality universities, its emphasis resides on the overall supply of an educated workforce, not necessarily capturing academic research and its associated effects. This allows us to address impacts arising from both academic research and teaching, thus offering a comprehensive perception of universities' impacts on innovation ecosystems.

Ancillary variables (included in the vector $\Omega$ ) control for market size (GDP, Population), agglomeration economies (Population Density), localization economies (Location Quotient of Knowledge-Intensive Activities - LQ KIA ${ }^{\mathrm{vi}}$ ), local infrastructure (Infrastructure Investments, Energy Consumption ${ }^{\text {vii }}$, and Incubators \& Science Parks), and internationalization (Trade). Although not exhaustive, these indicators offer a comprehensive set of controls for the dynamics of innovation ecosystems. 
Concerning our estimation strategy, as we are dealing with small numbers given the city/year structure of our analysis, analyses are carried out with General Linear Models for count data. Given the presence of overdispersion in the sample for both cities and microregions, Negative Binomial approaches are applied. Continuous variables are addressed via natural logs to simplify interpretation of results.

\section{RESULTS}

Before dedicating attention to results of model estimations, we present the descriptive statistics (Tables 2 and 3 ) for cities and microregions according to variables' natural structures (without logarithmic transformation). A noteworthy aspect in the dataset structure concerns the number of zeros in some variables. This is of particular relevance for city-level analysis. An outcome of this situation is the generation of missing values that significantly reduce the sample for econometric estimations, although it still leaves us with a substantial number of observations for analytical purposes.

Table 2. City-level descriptive statistics

\begin{tabular}{|c|c|c|c|c|c|}
\hline Variable & $\mathbf{N}$ & Minimum & Maximum & Mean & Std. Deviation \\
\hline Patents & 8385 & 0.00 & $1,444.00$ & 4.28 & 50.09 \\
\hline Software & 8385 & 0.00 & 237.00 & 0.60 & 8.36 \\
\hline KIE & 8385 & 0.00 & 33.00 & 0.10 & 1.07 \\
\hline GDP & 8385 & $6,233,930.00$ & $628,064,882,140.00$ & $1,705,420,922.98$ & $16,340,733,232.15$ \\
\hline Population & 8385 & 800.00 & $11,513,836.00$ & $62,590.08$ & $447,177.19$ \\
\hline Population Density & 8385 & 3.73 & $12,796.46$ & 294.47 & $1,170.44$ \\
\hline LQ KIA & 8385 & 0.00 & 5.25 & 0.49 & 0.42 \\
\hline Infrastructure Investments & 8385 & 0.00 & $4,397,255,759.00$ & $12,917,986.01$ & $117,447,952.00$ \\
\hline Energy Consumption & 8385 & 655.00 & $30,073,839.00$ & $180,139.83$ & $1,094,208.41$ \\
\hline Incubators and Science Parks & 8385 & 0.00 & 1.00 & 0.03 & 0.16 \\
\hline Trade & 8385 & 0.00 & $23,814,616,506.00$ & $154,078,636.26$ & $932,951,809.40$ \\
\hline Tertiary enrollment & 8385 & 0.00 & 0.28 & 0.01 & 0.02 \\
\hline High-Quality University & 8385 & 0.00 & 1.00 & 0.05 & 0.22 \\
\hline High-Quality Univ. System & 8385 & 0.00 & 1.00 & 0.01 & 0.12 \\
\hline
\end{tabular}

\section{Table 3. Microregion-level descriptive statistics}

\begin{tabular}{|c|c|c|c|c|c|}
\hline Variable & $\mathbf{N}$ & Minimum & Maximum & Mean & Std. Deviation \\
\hline Patents & 559 & 0,00 & $1.951,00$ & 64,18 & 256,71 \\
\hline Software & 559 & 0,00 & 281,00 & 9,02 & 37,54 \\
\hline $\mathrm{KIE}$ & 559 & 0,00 & 47,00 & 1,57 & 4,81 \\
\hline GDP & 559 & $691.797 .400,72$ & $723.802 .678 .913,45$ & 19.994.544.928,05 & 71.513.895.104,02 \\
\hline Population & 559 & $104.656,00$ & $19.875 .809,00$ & $938.851,14$ & $2.812 .857,11$ \\
\hline Population Density & 559 & 23,08 & $3.019,21$ & 245,87 & 586,63 \\
\hline LQ KIA & 559 & 0,18 & 1,59 & 0,47 & 0,22 \\
\hline Infrastructure Investments & 559 & 0,00 & $7.496 .336 .686,06$ & $208.066 .415,95$ & $698.684 .753,55$ \\
\hline Energy Consumption & 559 & $120.541,25$ & $58.805 .957,45$ & $3.048 .096,38$ & 8.398.491,30 \\
\hline Incubators and Science Parks & 559 & 0,00 & 1,00 & 0,28 & 0,45 \\
\hline Trade & 559 & 0,00 & $54.966 .359 .270,60$ & $1.972 .653 .288,99$ & $6.533 .900 .871,03$ \\
\hline Tertiary enrollment & 559 & 0,00 & 0,03 & 0,01 & 0,01 \\
\hline High-Quality University & 559 & 0,00 & 1,00 & 0,56 & 0,50 \\
\hline High-Quality Univ. System & 559 & 0,00 & 1,00 & 0,28 & 0,45 \\
\hline
\end{tabular}


We begin our assessment with an evaluation of the results for the city-level analysis. According to expectations presented in our theoretical background, the presence of high-quality universities demonstrates positive and significant impacts for all of the three dependent variables included in our estimations. This is valid for both variables representing these institutions (High-quality university and High-quality system). This results seem to confirm the existence of a 'co-location' effect in terms of universities' spillovers, as observed by Agrawal and Cockburn (2003), Cowan and Zinovyeva (2013) and Li (2009) regarding the generation of patents. Additionally, we verify that academic presence shows increased relevance as a driver of entrepreneurial activity (Bercovitz \& Feldman, 2006; Chen \& Kenney, 2007; Galan-Muros \& Davey, 2017; WEF, 2014).

Interestingly, for software deposits and KIE activity, the coefficient associated to the presence of at least one major university surmounts the effects of the existence of a system (at least two) of such institutions. Even for the case of patenting activity, the difference is not substantial. This is an interesting indication of the role played by even one preeminent, researchoriented university within the city-level dynamics of innovation ecosystems. In any case, the impacts of these universities present a dominant behavior respective to most of the other variables included in estimations.

Complementarily, when we address the levels of Tertiary Enrollment, it becomes clear that impacts arising from the provision of an educated workforce can be beneficial for the local innovative environment. However, these effects are much more limited than those perceived for high-quality academia. At least this seems to be the case for the State of São Paulo, Brazil. This situation highlights the strategic importance of major universities as research hubs that can benefit the generation of knowledge and the emergence of new, innovation-driven firms.

\section{Table 4. City-level estimations}

\begin{tabular}{|c|c|c|c|c|c|c|}
\hline \multirow{2}{*}{ Variable } & \multicolumn{2}{|c|}{ Patents } & \multicolumn{2}{|c|}{ Software } & \multicolumn{2}{|r|}{ KIE } \\
\hline & I & II & $\mathbf{I}$ & II & I & II \\
\hline Constant & $-4.078 * * *[.871]$ & $-3.224 * * *[.875]$ & $-4.799 * * *[1.876]$ & $-2.159[1.830]$ & $-3.507[2.504]$ & $-.494[2.504]$ \\
\hline GDP & $-.298 * * *[.100]$ & $-.383 * * *[.097]$ & $-.128[.249]$ & $-.391 *[.234]$ & $-.572 *[.317]$ & $-.778 * *[.305]$ \\
\hline Population & $.438 * * *[.095]$ & $.556 * * *[.093]$ & $-.829 * * *[.233]$ & $-544 * *[.219]$ & $-.013[.278]$ & $-.381[.277]$ \\
\hline Population Density & $.162 * * *[.036]$ & $.158 * * *[.036]$ & $.503 * * *[.095]$ & $.526^{* * *}[.096]$ & $-.029[.109]$ & $-.045[.107]$ \\
\hline LQ KIA & $.737 * * *[.086]$ & $.775^{* * *}[.087]$ & $1.241^{* * *}[.197]$ & $1.172 * * *[.195]$ & $.668 * *[.296]$ & $.693^{* *[.288]}$ \\
\hline Infrastructure Investments & $.001[.057]$ & $-.005[.056]$ & $.080[.155]$ & $.151[.149]$ & $.241[.194]$ & $.167[.188]$ \\
\hline Energy Consumption & $.389 * * *[.097]$ & $.401 * * *[.097]$ & $.877 * * *[.249]$ & $.855^{* * * *}[.244]$ & $.586 *[.300]$ & $.631 * *[.295]$ \\
\hline Incubators and Science Parks & $.857 * * *[.108]$ & $.751 * * *[.112]$ & $1.083^{* * *}[.255]$ & $1.090 * * *[.264]$ & $1.043 * * *[.240]$ & $.910 * * *[.271]$ \\
\hline Patents Binary & - & - & - & - & $.568[.389]$ & $.884 * *[.385]$ \\
\hline Software Binary & - & - & - & - & $.802^{* * *}[.214]$ & $.926 * * *[.212]$ \\
\hline Trade & $.070 * * *[.022]$ & $.061 * * *[.022]$ & $.125 *[.073]$ & $.086[.069]$ & $.089[.084]$ & $.009[.078]$ \\
\hline Tertiary enrollment & $.014[.031]$ & $.057 *[.030]$ & $.393 * * *[.093]$ & $.502 * * *[.090]$ & $.072[.118]$ & $.268^{* *[.111]}$ \\
\hline High-Quality University & $.604 * * *[.094]$ & - & $1.233 * * *[.228]$ & - & $1.661 * * *[.226]$ & - \\
\hline High-Quality Univ. System & - & $.829 * * *[.140]$ & - & $1.192 * * *[.299]$ & - & $1.283^{* * *}[.288]$ \\
\hline Alpha & $.875^{* * * *[.049]}$ & $.877 * * *[.049]$ & $3.032 * * *[.275]$ & $3.083 * * *[.282]$ & $2.080 * * *[.337]$ & $2.371 * * *[.384]$ \\
\hline Overdispersion & Yes & Yes & Yes & Yes & Yes & Yes \\
\hline Valid N & 1319 & 1319 & 1319 & 1319 & 1319 & 1319 \\
\hline Std. Errors in brackets & *sig. at & $10 \%$; **sig. at $5 \%$ & $* * *$ sig. at $1 \%$ & & & \\
\hline
\end{tabular}

A general evaluation of the other variables included in estimations renders some noteworthy findings. For instance, agglomeration economies associated to population density seem to be present for patenting activity and software production, following an extant literature on the geography of innovation (e.g. Florida \& Mellander, 2014). However, these effects do 
not drive entrepreneurial activity, supporting recent evidence in the field (Fischer et al., 2018b). Another vector of high relevance concerns the existence of a support structure of local businesses in knowledge-intensive activities, a marked signal of localization economies as drivers of innovation ecosystems' capabilities (Delgado et al., 2010). In its turn, incubators and science parks seem to play an important role in shaping local conditions for innovative output. Surprisingly, levels of city-level internationalization are weakly related to dependent variables, with the exception of patenting activity. Infrastructural conditions also perform as expected, providing innovation ecosystems with the necessary operational platforms - nonetheless, this is valid solely for the proxy Energy Consumption.

Turning to the analysis of microregions, we can notice that effects associated to our three university-related variables (Tertiary enrollment, High-quality university and High-quality university system) are significantly diminished as compared to findings observed for the citylevel analysis. Still, some significant impacts can still be observed, but with consistently reduced coefficients. This carries with it theoretical and methodological implications. From the perspective of theory, it implies that geographical spillovers are frail and that higher education institutions' impacts on innovation ecosystems dynamics are mostly constrained to the level of cities. From a methodological point of view, this means that analytical approaches to these ecosystems should be directed to these smaller geographic units.

As per the remaining variables, some changes can be noticed. Remarkably, the role of GDP is inverse as what was noticed for the previous step in the assessment. Latent agglomeration economies associated to population density vanish. This can be deemed as an expected outcome, as benefits from agglomeration are likely to be weaker when larger areas are under scrutiny. Localization economies continue playing an important role, underscoring the strategic weight of a support business structure. In its turn, infrastructural conditions lose importance, except for the specific case of business incubators and science parks. Again, internationalization levels perform poorly as drivers of output within the realm of innovation ecosystems.

Table 5. Microregion-level estimations

\begin{tabular}{|c|c|c|c|c|c|c|}
\hline \multirow{2}{*}{ Variable } & \multicolumn{2}{|c|}{ Patents } & \multicolumn{2}{|c|}{ Software } & \multicolumn{2}{|c|}{ KIE } \\
\hline & I & II & I & II & I & II \\
\hline Constant & $-10.614 * * *[1.755]$ & $-12.106^{* * * *[1.724]}$ & $-27.160 * * *[3.837]$ & $-27.323 * * *[3.609]$ & $-35.002[89.553]$ & $-31.191[81.024]$ \\
\hline GDP & $.430 * *[.177]$ & $.474 * * *[.179]$ & $1.799^{* * * *[.380]}$ & $1.837 * * *[.372]$ & $1.355^{* *}[.552]$ & $\left.1.355^{* *} * .572\right]$ \\
\hline Population & $.710^{* * * *[.157]}$ & $.671^{* * * *[.160]}$ & $-.360[.344]$ & $-.323[.340]$ & $-.210[.443]$ & $-.361[.456]$ \\
\hline Population Density & $.026[.065]$ & $-.031[.063]$ & $-.020[.155]$ & $-.055[.154]$ & $-.381[.238]$ & $-.356[.245]$ \\
\hline LQ KIA & $.665^{* * *}[.141]$ & $.517 * * *[.141]$ & $.681 * *[.304]$ & $.784 * * *[.294]$ & $1.295 * * *[.402]$ & $.772 *[.417]$ \\
\hline Infrastructure Investments & $-.314 * * *[.089]$ & $-.251 * * *[.090]$ & $-.239[.206]$ & $-.296[.206]$ & $-.624 * *[.257]$ & $-.443 *[.260]$ \\
\hline Energy Consumption & $.220 * *[.105]$ & $.255^{* *}[.105]$ & $-.004[.205]$ & $-.001[.201]$ & $.218[.275]$ & $.354[.281]$ \\
\hline Incubators and Science Parks & $.673^{* * *}[.095]$ & $.737 * * *[.096]$ & $.545^{* *}[.214]$ & $.618^{* * *[.206]}$ & $1.022 * * *[.244]$ & $1.179 * * *[.237]$ \\
\hline Patents Binary & - & - & - & - & $24.957[89.553]$ & $18.633[81.024]$ \\
\hline Software Binary & - & - & - & - & $.640 * * *[.240]$ & $.595^{* *}[.247]$ \\
\hline Trade & $-.159 * * *[.043]$ & $-.175 * * *[.044]$ & $-.125[.113]$ & $-.117[.111]$ & $-.273 *[.144]$ & $-.325 * *[.143]$ \\
\hline Tertiary enrollment & $-.086[.053]$ & $-.073[.054]$ & $.239 *[.139]$ & $.250 *[.136]$ & $.647 * * *[.209]$ & $.616 * * *[.218]$ \\
\hline High-Quality University & $.400^{* * *}[.092]$ & - & $-.070[.223]$ & - & $1.068 * * *[.316]$ & - \\
\hline High-Quality Univ. System & - & $.251 * * *[.094]$ & & $-.301[.199]$ & - & $.721 * * *[.240]$ \\
\hline Alpha & $.390 * * *[.035]$ & $.408^{* * * *[.036]}$ & $1.150 * * *[.169]$ & $1.118 * * *[.168]$ & $1.100 * * *[.235]$ & $1.168 * * *[.246]$ \\
\hline Overdispersion & Yes & Yes & Yes & Yes & Yes & Yes \\
\hline Valid $\mathbf{N}$ & 386 & 386 & 386 & 386 & 386 & 386 \\
\hline Std. Errors in brackets & *sig. & $10 \% ; * *$ sig. at $5 \%$ & $* *$ sig. at $1 \%$ & & & \\
\hline
\end{tabular}




\section{CONCLUDING REMARKS}

In this article we have assessed the role of universities in shaping the dynamics of innovation ecosystems within the context of a developing country, Brazil. In order to do so, we designed empirical approach that tests the relevance of the presence of high-quality universities in a given location, as well as overall supply of qualified workforce (regardless of quality of the alma mater). We then approached three outcome vectors of innovative activity, namely: patenting activity, software registration and knowledge-intensive entrepreneurship. Drawing from data from the State of São Paulo, we found consistent indications that major academic institutions lie at the heart of innovation ecosystems, corroborating with the 'anchor' proposition outlined in Xu et al. (2017). While formation of human capital also contributes to innovative output, its impacts are of minor relevance as compared to higher education institutions that achieve excellence in research.

These results highlight not only the importance of universities in structuring successful ecosystems, but it also indicates that fomenting research in these agents can have pervasive impacts upon socioeconomic development at the local level. Yet, there remains the challenge of further integrating academia to markets in Brazil. Achieving closer interactions between universities and productive systems can boost technological innovation and, consequently, catching up dynamics (Caraça et al., 2009; Cohen et al., 2002; Jiao et al., 2016; Li, 2009). However, in the Brazilian context, these interconnections still suffer from institutional and market deficiencies (Fischer et al., 2017; Fischer at al., 2018a). Improvements in the conditions and incentives for these interactions, as we have demonstrated, can prove to be a fruitful strategy for the Brazilian Innovation System.

Interestingly, our empirical approach suggests that such effects are mostly circumscribed to cities, signalling that larger regions might not be adequate geographic units for innovation ecosystems' analytical purposes (Audretsch \& Belitski, 2017; Bruns et al., 2017; Qian et al., 2013). This finding emphasizes the importance of spatial proximity (Fritsch \& Schwirten, 2006), but it also draws attention to the geographical limits of innovation spillovers. These conditions bring significant implications on the way innovation policies at the regional level should be addressed, as connections among ecosystems' dimensions seem to happen within restricted areas.

This poses severe challenges for policymakers when targeting the formation and enhancement of fomenting innovation ecosystems, particularly for peripheral areas. First, as outlined by our findings, these regions are not likely to reap substantial benefits from proximity to successful hubs - if that is the case in the first place. Beyond that, creating local conditions is not as straightforward as sometimes announced in political discourses. Establishing incubators and science parks is fine, but such initiatives are only part of ecosystems' structures. In this regard, some fundamental vectors are not easily manipulated within the short-term, and there seems to be a fundamental importance attributed to long-term, evolutionary conditions. Such is the case for high-quality universities. These institutions cannot be simply instated in a given location by fiat, as new campuses may take an extensive amount of time to mature into preeminent schools and research centers. Complementarily, leading institutions are not likely to open new units indefinitely, leaving many locations without the key presence of these drivers of innovation at the local-level.

We expect our contributions to generate further research on the role of academia in shaping the dynamics of innovation ecosystems of developing countries. While case studies and econometric analyses exist for developed economies, there are scant approaches dealing with

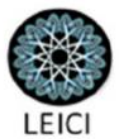


the reality of relatively laggard systems, where connections between agents are still immature (Rapini et al., 2009). Avenues for future studies should include additional and alternative qualifications of university presence, as well as digging into the qualitative nature of academic research as a driver for innovative activity at the city-level. These appraisals will help creating a body of knowledge that can feed the policymaking process with more informative insights than those generated by anecdotal evidence collected from dissimilar contexts.

\section{REFERENCES}

Ács, Z. J., Anselin, L., \& Varga, A. (2002). Patents and innovation counts as measures of regional production of new knowledge. Research Policy, 31(7), 1069-1085.

Agrawal, A., \& Cockburn, I. (2003). The anchor tenant hypothesis: exploring the role of large, local, R\&D-intensive firms in regional innovation systems. International Journal of Industrial Organization, 21(9), 1227-1253.

Alcácer, J., \& Chung, W. (2007). Location strategies and knowledge spillovers. Management Science, 53(5), 760-776.

Alvedalen, J., \& Boschma, R. (2017). A critical review of entrepreneurial ecosystems research: towards a future research agenda. European Planning Studies, 25(6), 887-903.

Asheim, B., \& Coenen, L. (2005). Knowledge Bases and Regional Innovation Systems: comparing Nordic clusters. Research Policy, 34(8), 1173-1190.

Asheim, B., \& Isaken, A. (2002). Regional Innovation Systems: the integration of local 'sticky' and global 'ubiquitous' knowledge. Journal of Technology Transfer, 27(1), 77-86.

Asheim, B., Smith, H., \& Oughton, C. (2011). Regional Innovation Systems: Theory, Empirics and Policy. Regional Studies, 45(7), 875-891.

Audretsch, D., \& Belitski, M. (2017). Entrepreneurial ecosystems in cities: establishing the framework conditions. Journal of Technology Transfer, 42(5), 1030-1051.

Autio, E. (1998). Evaluation of RTD in regional systems of innovation. European Planning Studies, 6(2), 131-140.

Benneworth, P., \& Hospers, G. J. (2007). The new economic geography of old industrial regions: universities as global-local pipelines. Environment and Planning, 25(6), 779-802.

Bercovitz, J., \& Feldman, M. (2006). Entrepreneurial universities and technology transfer: a conceptual framework for understanding knowledge-based economic development. Journal of Technology Transfer, 31(1), 175-188.

Boschma, R. (2005). Proximity and innovation: a critical assessment. Regional Studies, 39(1), 61-74.

Breschi, S., \& Lissoni, F. (2009). Mobility of skilled workers and co-invention networks: an anatomy of localized knowledge flows. Journal of Economic Geography, 9(4), 439-468.

Brown, R. (2016). Mission impossible? Entrepreneurial universities and peripheral regional innovation systems. Industry and Innovation, 23(2), 189-205.

Bruns, K., Bosma, N., Sanders, M., \& Schramm, M. (2017). Searching for the existence of entrepreneurial ecosystems: a regional cross-section growth regression approach. Small Business Economics, 49(1), 31-54.

Buesa, M., Heijis, J., \& Baumert, T. (2010). The determinants of regional innovation in Europe: a combined factorial and regression knowledge production function approach. Research Policy, 39(6), 722-735.

Buesa, M., Heijis, J., Pollitero, M. M., \& Baumert, T. (2006). Regional systems of innovation and the knowledge production function: the Spanish case. Technovation, 26(4), 463-472.

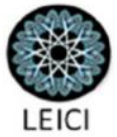


Caraça, J., Lundvall, B., \& Mendonça, S. (2009). The changing role of science in the innovation process: from queen to Cinderella? Technological Forecasting and Social Change. 76(6), 861-867.

Chen, K., \& Kenney, M. (2007). Universities/Research Institutes and Regional Innovation Systems: the cases of Beijing and Shenzhen. World Development, 35(6), 1056-1074.

Clark, B. (2004). Creating Entrepreneurial Universities. Oxford: IAU Press-Elsevier.

Clarysse, B., Wright, M., Bruneel, J., \& Mahajan, A. (2014). Creating value in ecosystems: Crossing the chasm between knowledge and business ecosystems. Research Policy, 43(7), 1164-1176.

Cohen, W. M., Nelson, R. R., \& Walsh, J. P. (2002). Links and impacts: The influence of public research on industrial R\&D. Management Science, 48(1), 1-23.

Collini, S. (2012). What Are Universities for? London: Penguin.

Cooke, P. (2001). Regional Innovation Systems, Clusters and the Knowledge Economy. Industrial and Corporate Change, 10(4), 945-974.

Cooke, P. (2005). Regionally asymmetric knowledge capabilities and open innovation: exploring 'globalisation 2' - a new model of industry organization. Research Policy, 34(8), 1128-1149.

Cooke, P. (2008). Regional innovation systems: origin of the species. International Journal of Technological Learning, Innovation and Development, 1(3), 393-409.

Cooke, P., Uranga, M., \& Etxebarria, G. (1997). Regional innovation systems: Institutional and organizational dimensions. Research Policy, 26(4), 475-491.

Cooke, P., Uranga, M., \& Etxebarria, G. (1998). Regional systems of innovation: an evolutionary perspective. Environment and Planning, 30(9), 1563-1584.

Cowan, R., \& Zinovyeva, N. (2013). University effects on regional innovation. Research Policy, 42(3), 788-800.

D'Este, P., \& Perkmann, M. (2011). Why do academics engage with industry? The entrepreneurial university and individual motivations. Journal of Technology Transfer, 36(3), 316-339.

Delgado, M., Porter, M., \& Stern, S. (2010). Clusters and entrepreneurship. Journal of Economic Geography, 10(4), 495-518.

Diez, J. (2000). The importance of public research institutes in innovative networks-empirical results from the Metropolitan innovation systems Barcelona, Stockholm and Vienna. European Planning Studies, 8(4), 451-463.

Doloreux, D. (2002). What we should know about regional systems of innovation. Technology in Society, 24(3), 243-263.

Doloreux, D., \& Parto, S. (2005). Regional innovation systems: current discourse and unresolved issues. Technology in Society, 27(2), 133-153.

Dosi, G. (1988). The nature of the innovative process. In: Dosi, G. et al. (eds.). Technical Change and Economic Theory. London: Pinter.

Etzkowitz, H. (1998). The norms of entrepreneurial science: cognitive effects of the new university-industry linkages. Research Policy, 27(8), 823-833.

Etzkowitz, H. (2004). The evolution of the entrepreneurial university. International Journal of Technology and Globalization, 1(1), 64-77.

Etzkowitz, H., \& Leydesdorff, L. (2000). The dynamics of innovation: from National Systems and "Mode 2" to a Triple Helix of university-industry-government relations. Research Policy, 29(2), 109-123. 
Feldman, M. P. (2001). The Entrepreneurial Event Revisited: firm formation in a regional context. Industrial and Corporate Change, 10(4), 861-891.

Fischer, B. (2015). On the Contributions of Knowledge-Intensive Business-Services Multinationals to Laggard Innovation Systems. Brazilian Administration Review, 12(2), 150-168.

Fischer, B., Schaeffer, P., Vonortas, N., \& Queiroz, S. (2017). Quality comes first: universityindustry collaboration as a source of academic entrepreneurship in a developing country. Journal of Technology Transfer, forthcoming (pre-print available online).

Fischer, B., Schaeffer, P., \& Phaiffer, J. (2018a). Universities' gravitational effects on the location of knowledge-intensive investments in Brazil. Science and Public Policy, forthcoming (pre-print available online).

Fischer, B., Queiroz, S., \& Vonortas, N. (2018b). On the location of knowledge-intensive entrepreneurship in developing countries: lessons from São Paulo, Brazil. Entrepreneurship and Regional Development, forthcoming (pre-print available online).

Florida, R., \& Mellander, C. (2014). Rise of the startup city: the changing geography of the venture capital financed innovation. [Working Paper n. 377]. Centre of Excellence for Science and Innovation Studies.

Fritsch, M. (2001). Co-operation in regional innovation systems. Regional Studies, 35(4), $297-$ 307.

Fritsch, M. (2005). Do regional systems of innovation matter? In: Huebner, K. (eds.). The New Economy in Transatlantic Perspective: spaces of innovation. London: Taylor \& Francis.

Fritsch, M., \& Schwirten, C. (2006). Enterprise-University co-operation and the role of public research institutions in regional innovation systems. Industry and Innovation, 6(1), 69-83.

Fritsch, M., \& Slavtchev, V. (2007). Universities and innovation in space. Industry and Innovation, 14(2), 201-218.

Galan-Muros, V., \& Davey, T. (2017). The UBC ecosystem: putting together a comprehensive framework for university-business cooperation. Journal of Technology Transfer, forthcoming (pre-print available online).

Giuliani, E. (2013). Network Dynamics in Regional Cluster: evidence from Chile. Research Policy, 42(8), 1406-1419.

Guerrero, M., Urbano, D., Fayolle, A., Klofsten, M., \& Mian, S. (2016). Entrepreneurial universities: emerging models in the new social and economic landscape. Small Business Economics, 47(3), 551-563.

Harrison, R. T., \& Leitch, C. (2010). Voodoo institution or entrepreneurial university? Spinoffs companies, the entrepreneurial system and regional development in the UK. Regional Studies, 44(9), 1241-1262.

Hicks, D., Breitzman, T., Olivastro, D., \& Hamilton, K. (2001). The changing composition of innovative activity in the US: a portrait based on patent analysis. Research Policy, 30(4), 681-703.

Hong, W. (2008). Decline of the center: the decentralizing process of knowledge transfer of Chinese universities from 1985 to 2004. Research Policy, 37(4), 580-595.

Jackson, D. J. (2011). What is an Innovation Ecosystem. Arlington (VA): National Science Foundation.

Jaffe, A. B. (1989). Real effects of academic research. The American Economic Review, 79(5), 957-970.

Jiao, H., Zhou, J., Gao, T., \& Liu, X. (2016). The more interactions the better? The moderating effect of the interaction between local producers and users of knowledge on the relationship 
between R\&D investment and regional innovation systems. Technological Forecasting and Social Change, 110, 13-20.

Laursen, K., Reichstein, T., \& Salter, A. (2011). Exploring the effect of geographical proximity and university quality on university-industry collaboration in the United Kingdom. Regional Studies, 45(4), 507-523.

Leydesdorff, L., \& Fritsch, M. (2006). Measuring the knowledge base of regional innovation systems in Germany in terms of a Triple Helix dynamics. Research Policy, 35(10), 15381553.

Li, X. (2009). China's regional innovation capacity in transition: an empirical approach. Research Policy, 38(2), 338-357.

Mazzoleni, R., \& Nelson, R. (2007). The roles of research at universities and public labs in economic catch-up. Research Policy, 36(10), 1512-1528.

Moodysson, J., Coenen, L., \& Asheim, B. (2008). Explaining spatial patterns of innovation: analytical and synthetic modes of knowledge creation in the Medicon Valley life-science cluster. Environmental Planning A, 40(5), 1040-1056.

Morrison, A., Rabellotti, R., \& Zirulia, L. (2013). When do Global Pipelines Enhance the Diffusion of Knowledge in Clusters? Economic Geography, 1(89), 77-96.

Mowery, D. C., \& Sampat, B. N. (2005). Universities in national systems. In: Fagerberg, J., Mowery, D., \& Nelson, R. (eds.). The Oxford Handbook of Innovation. Oxford: Oxford University Press.

Ortega-Argilés, R., Potters, L., \& Vivarelli, M. (2011). R\&D and productivity: testing sectoral peculiarities using micro data. Empirical Economics, 41(3), 817-839.

Poods, R., Oort, F., \& Frenken, K. (2010). Innovation, spillovers and university-industry collaboration: an extended knowledge production function approach. Journal of Economic Geography, 10(2), 231-255.

Perkmann, M., Tartari, V., McKelvey, M., Autio, E., Broström, A., D’Este, P., Fini, R., Geuna, A., Grimaldi, R., Hughes, A., Krabel, S., Kitson, M., Llerena, P., Lissoni, F., Salter, A., \& Sobrero, M. (2013). Academic engagement and commercialisation: a review of the literature on university-industry relations. Research Policy, 42(2), 423-442.

Qian, H., Ács, Z., \& Stough, R. (2013). Regional systems of entrepreneurship: the nexus of human capital, knowledge and new firm formation. Journal of Economic Geography, 13(4), 559-587.

Rapini, M. S., Albuquerque, E. D. M., Chave, C. V., Silva, L. A., Souza, S. G. A., Righi, H. M., \& Cruz, W. M. S. (2009). University-industry interactions in an immature system of innovation: Evidence from Minais Gerais, Brazil. Science and Public Policy, 36(5), $373-$ 386.

Saxenian, A. L. (2006). The New Argonauts: regional advantage in a global economy. Cambridge (MA): Harvard University Press.

Siegel, D. S., \& Wright, M. (2015). Academic Entrepreneurship: Time for a Rethink? British Journal of Management, 26(4), 582-595.

Suzigan, W., \& Albuquerque, E. (2011). The underestimated role of universities for the Brazilian system of innovation. Brazilian Journal of Political Economy, 31(1), 3-30.

Suzigan, W., Albuquerque, E., Garcia, R., \& Rapini, M. (2009). University and industry linkages in Brazil: some preliminary and descriptive results. Seoul Journal of Economics, 22(4), 591-611.

Uyarra, E. (2010). What is evolutionary about 'regional systems of innovation'? Implications for regional policy. Journal of Evolutionary Economics, 20, 115-137. 
Wal, A. L. J. T., \& Boschma, R. (2009). Applying social network analysis in economic geography: framing some key analytic issues. Annals of Regional Science, 43(3), 739-756.

Wef. (2013). Entrepreneurial Ecosystems Around the Globe and Company Growth Dynamics. Annual Meeting of the New Champions. Available at: < http://www3.weforum.org/docs/WEF_EntrepreneurialEcosystems_Report_2013.pdf >.

Wef. (2014). Entrepreneurial Ecosystems and around the Globe and Early-stage Company Growth Dynamics: An Entrepreneurs Perspective. Geneva: World Economic Forum.

Youtie, J., \& Shapira, P. (2008). Building an innovation hub: a case study of the transformation of university roles in regional technological and economic development. Research Policy, 37(8), 1188-1204.

Xu, G., Wu, Y., Minshall, T., \& Zhou, Y. (2017). Exploring innovation ecosystems across science, technology, and business: a case of 3D printing in China. Technological Forecasting and Social Change, forthcoming (pre-print available online).

\section{APPENDIX I. Knowledge-Intensive Sectors used for the Location Quotient (LQ KIA)} Analysis (NACE Rev. 2 - 2 Digits)

Manufacture of chemicals and chemical products (20), Manufacture of rubber and plastic products (22), Manufacture of computer, electronic and optical products (26), Manufacture of motor vehicles, trailers and semitrailers (29), Repair and installation of machinery and equipment (33), Computer programming, consultancy and related activities (62), Information service activities (63), Activities auxiliary to financial services and insurance activities (66), Legal and accounting activities (69), Activities of head offices; management consultancy activities (70), Architectural and engineering activities; technical testing and analysis (71), Scientific research and development (72), Advertising and market research (73), Other professional, scientific and technical activities (74).

${ }^{\mathrm{i}}$ According to the definition of microregions adopted by the São Paulo Statistics Office. Their nomenclature refers to these geographic areas as 'Regions of Government'.

ii The quotient is given by $\frac{\frac{K I A_{i t}}{T I A_{S t}}}{\frac{K A_{S t}}{T F_{S t}}}$, where KIA corresponds to total knowledge-intensive firms and TF represents total firms. First, we assess KIA's weight in location " $\mathrm{i}$ ", period " $\mathrm{t}$ " as a share of TF in this location, and then analyze the local specialization respective to the State ("S") profile.

iii It is important to highlight that academic degrees or formal appointments at universities are not requisites for granting funds to projects. Instead, priority is given to individuals with previous professional experience and technical capabilities. This feature of PIPE substantively reduces biases towards cities that contain university campuses.

${ }^{\text {iv }}$ Provided that these variables present extreme levels of concentration (particularly for city-level analysis), their treatment as predictors becomes troublesome. See details on estimation procedures for these indicators as dependent variables below.

For further details on the Scimago Institutions Rankings Methodology: http://www.scimagoir.com/methodology.php. For years not covered by the ranking we applied the same methodology of inclusion as the one used by Scimago.

${ }^{\text {vi }}$ Knowledge-intensive activities comprehend an adaptation of the definitions provided by Ortega-Argilés et al. (2011) for high-technology manufacturing activities, and Fischer (2015) for Knowledge-Intensive Business Services (KIBS).

vii As infrastructure investments may suffer from simultaneity issues, we use energy consumption as a proxy for infrastructural quality (as in Fischer et al., 2018a). 